\title{
Translating the Patient Navigator Approach to Meet the Needs of Primary Care
}

Jeanne M. Ferrante, MD, MPH, Deborah J. Cohen, PhD, and Jesse C. Crosson, PhD

Background: Helping patients navigate the complex and fragmented US health care system and coordinating their care are central to the patient-centered medical home. We evaluated the pilot use of a patient navigator (PN), someone who helps patients use the health care system effectively and efficiently, in primary care practices.

Methods: This study was a cross-case comparative analysis of 4 community practices that implemented patient navigation. Project meeting notes, PN activity logs and debriefings, physician interviews, and patient/family member interviews were analyzed using a grounded approach.

Results: Seventy-five mostly female, elderly patients received navigation services from a social worker. The PN typically helped patients obtain social services and navigate health coverage and complex referrals. Availability of workspace for PN, interaction with practice members, and processes used for selecting and referring patients affected PN collaboration with and integration into practices. Patients found PN services very helpful, and physicians viewed the PN as someone carrying out new tasks that the practice was not previously doing.

Conclusions: Patient navigation in community primary care practices is useful for patients who have complex needs. Integrating such services into primary care settings will require new practice and payment models to realize the full potential of integrated patient navigation services in this setting. (J Am Board Fam Med 2010;23:736-744.)

Keywords: Patient Navigation, Patient-Centered Care, Medical Home, Qualitative Research, Practice-Based Research, Delivery of Health Care

There is widespread endorsement of the patientcentered medical home $(\mathrm{PCMH})$ as a new model of care to reform the US health care system into one that is more patient centered, accessible, effective, safer, and efficient. ${ }^{1,2}$ Currently, the US health care system is complex, confusing, and fragmented, ${ }^{3}$ and

This article was externally peer reviewed.

Submitted 8 April 2010; revised 21 June 2010; accepted 23 June 2010.

From the Department of Family Medicine and Community Health, University of Medicine and Dentistry of New Jersey-Robert Wood Johnson Medical School, New Brunswick (JMF, JCC); the Cancer Institute of New Jersey, New Brunswick (JMF); and the Department of Family Medicine, Oregon Health \& Science University (DJC).

Funding: This research was supported through grants from the Overlook Hospital Foundation (JMF) and University of Medicine and Dentistry of New Jersey Team Science Initiative (JMF, DJC, JCC).

Prior Presentation: Portions of this manuscript have been presented at the 37th North American Primary Care Research Group Annual Meeting, Montreal, Canada (November 14-18, 2009).

Conflict of interest: none declared.

Corresponding author: Jeanne M. Ferrante, MD, MPH, 1 World's Fair Drive, Suite 1515, Somerset, NJ 08873 (E-mail: ferranjm@umdnj.edu). helping patients better navigate this system and coordinating the care they receive are central to the PCMH. ${ }^{4}$ However, how best to accomplish these functions in primary care practice remains unclear. ${ }^{5}$ Although many PCMH demonstration projects are focusing on information technology (IT) ${ }^{6}$ to help primary care physicians better track and monitor patients, less effort has been directed at helping patients navigate the health care system to ensure that they receive the care they need at the right time. Ineffective navigation of the health care system by patients may lead to poorer outcomes and inefficiencies because of delayed care, failure to receive proper care or treatments, or care being received in more expensive locations (ie, emergency rooms). ${ }^{7}$

Patient navigation may be defined as the process of helping patients to effectively and efficiently use the health care system. Sofaer ${ }^{7}$ describes 4 major challenges patients face when navigating our complex system: (1) choosing, understanding, and using health coverage or applying for assistance when uninsured; (2) choosing, using, and understanding 
different types of health providers and services; (3) making treatment decisions; and (4) managing care received by multiple providers. Although primary care practices are often expected to assist patients in meeting these challenges, the majority of practices cannot assume this role effectively because of perceived time, personnel, and reimbursement constraints. Efforts to address patient navigation challenges have been successfully implemented in other organizations (eg, cancer centers), and these programs potentially may be translated to community primary care settings.

Cancer care programs have widely implemented the use of nurses, social workers, and trained peer counselors or lay persons as patient navigators (PNs) to provide education, psychosocial support, and assistance to patients when accessing and using needed services. ${ }^{8,9}$ The use of PNs in these settings has been successful in increasing rates of cancer screening and adherence to follow-up care after an abnormal screening while increasing patient satisfaction and decreasing anxiety. ${ }^{10-14}$ Similarly, health plans and integrated delivery systems have used care managers or care coordinators to focus on high-risk, high-cost patients who have a single disease (eg, diabetes or asthma) to ensure they receive services they need. ${ }^{5}$ These $\mathrm{PN}$ and care manager programs usually focus on patients who have a single disease; additionally, these programs use PNs in cancer settings or care managers who are external to practices. No one has described the use of a $\mathrm{PN}$ in primary care settings for patients who have a variety of health problems.

The use of a dedicated person to assist patients in meeting the navigation challenges described above by Sofaer, ${ }^{7}$ is a potential strategy to help achieve collaborative, team-based care in the PCMH, but little is known about the feasibility of this strategy in community-based primary care settings. We present the results of a qualitative evaluation of the implementation and use of a pilot $\mathrm{PN}$ program in 4 community practices and describe the barriers and facilitators to integrating this new role in these settings. Goals of this qualitative evaluation were (1) to elicit insights into the process of establishing PN services; (2) to understand the barriers and facilitators to $\mathrm{PN}$ use in the primary care setting; and (3) to gain an in-depth understanding of patient and physician experiences with PN services.

\section{Methods}

\section{Project Background, Design, and Implementation}

A solo physician participant in the American Academy of Family Physicians' PCMH National Demonstration Project, ${ }^{15}$ was the lead physician for the demonstration project. While participating in the National Demonstration Project, he found that his practice could implement IT elements of a PCMH but lacked resources to accomplish personalized, relationship-centered tasks. With funding from a local hospital foundation, this physician recruited 3 other physicians to pilot the addition of a $\mathrm{PN}$ to their practices. The 4 physicians included 2 family physicians (1 man and 1 woman) and 2 internal medicine physicians (both men). The lead physician was in solo practice and the other 3 physicians worked in small group practices (consisting of 2, 3, and 4 physicians). PN services were planned for only one physician per practice. All practices were located in suburban New Jersey, and 2 used electronic medical records.

Doctors planned for the $\mathrm{PN}$ to provide coordination of social services and complex referrals and to facilitate information exchange between the primary care office, specialist offices, and the patient. They hired a social worker as the PN, and her services were shared by the 4 physicians. The physicians met together with the PN to determine what types of patients to refer (see Table 1) and the expected role and activities of the PN. The PN then met with each physician separately at his/her office to discuss her schedule, role, referral of patients, and communication procedures with the physician and other staff members. It was anticipated that the PN would spend one day per week at each practice. Physicians prospectively generated a list of patients who they felt could benefit from the services of the PN. The PN contacted these patients, assessed patient needs to optimize health

\section{Table 1. Patient Selection Criteria for Referral to Patient Navigator}

1. Patients who were seeing multiple specialists

2. Patients who were using internal resources frequently (high staff demands, frequent phone calls or visits)

3. Patients requiring social services

4. Patients needing a difficult or complex referral

5. Patients who were homebound

6. Patients who were having family communication issues

7. Patients requiring mental health or pain management coordination 
care, and worked with the patients until those needs were met.

\section{Project Evaluation}

The research team was contracted to conduct an independent evaluation of the project. The data collected and analyzed are listed in Table 2. Data were collected during the 12-month implementation period. The only exception was patient interviews, which were conducted with patients after $\mathrm{PN}$ services were delivered. Patient interviews continued until data saturation was reached $(\mathrm{n}=15)$. Data were de-identified and imported into ATLAS.ti software (Atlas.ti Scientific Software Development $\mathrm{GmbH}$, Berlin, Germany) for coding and analysis. The Institutional Review Board of the University of Medicine and Dentistry of New Jersey-Robert Wood Johnson Medical School approved this study, and all participants provided informed consent.

To analyze the data we used a grounded approach that involved a series of immersion/crystallization cycles. ${ }^{16}$ This approach involved immersing oneself in the data through cycles of readings and reflections, gaining insights and themes as they emerge, until reportable interpretations became apparent and crystallize. Initially, the evaluation team (JMF, DJC, and JCC) read transcripts jointly to understand the content and to develop a set of preliminary emergent codes. Group analysis continued until consensus was reached regarding coding schemes. The remaining data was then independently analyzed, and the evaluation team met regularly to discuss interpretations and to refine coding schemes as needed. Next, data within codes were reread and analyzed in a second immersion/ crystallization cycle using data from the multiple sources (eg, meeting notes, navigator debriefings, and patient and physician interviews). Our goal was to develop a refined understanding of the emerging themes and to identify how these themes were manifest across different perspectives (patient, physician, PN). Through this process we identified the quotations included in this article that represent and most succinctly illustrate key findings.

\section{Results}

We identified several barriers and facilitators to the integration of the $\mathrm{PN}$ in this project. The following sections describe the delivery of PN services, factors affecting collaboration and integration, and the perceived value of $\mathrm{PN}$ services by patients and physicians.

\section{Delivery of Patient Navigator Services}

The PN helped 75 patients during the 12-month study period. The PN had many tasks related to start-up during the earlier months, data collection,

Table 2. Data Reviewed for Qualitative Analysis

\begin{tabular}{|c|c|c|}
\hline Data & Description & Examples \\
\hline Meeting notes & $\begin{array}{l}\text { Project meetings conducted before, during, and at the end of } \\
\text { the project }\end{array}$ & $\begin{array}{l}\text { - Agenda and minutes } \\
\text { - E-mail communications } \\
\text { - Original grant application }\end{array}$ \\
\hline Navigator $\log$ & $\begin{array}{l}\text { Tool used to track activities of navigator, focus navigator } \\
\text { debriefings, and select patients for interviews. }\end{array}$ & $\begin{array}{l}\text { - Medical conditions of patients } \\
\text { - Number of contacts made } \\
\text { - Services provided } \\
\text { - Patient barriers } \\
\text { - Community resources accessed }\end{array}$ \\
\hline Navigator debriefings & $\begin{array}{l}\text { 1-hour telephone sessions every } 2-4 \text { weeks with research team } \\
\text { member } \\
\text { Helped navigator reflect on her work and allowed her to discuss } \\
\text { experiences with patients so detailed notes were not needed }\end{array}$ & - Audio recordings and transcriptions \\
\hline Patient interviews & $\begin{array}{l}\text { In-depth telephone interviews }(15-45 \mathrm{~min}) \text { with } 15 \text { patients or } \\
\text { their family members } \\
\text { Conducted at the end of the project. Patients were purposely } \\
\text { selected by the research team after review of navigator logs } \\
\text { to maximize richness and variability of patient experiences } \\
\text { Included patients who did not need many services }\end{array}$ & - Audio recordings and transcriptions \\
\hline Physician interviews & $\begin{array}{l}\text { In-depth, face-to-face interviews }(20-40 \mathrm{~min}) \text { with all } \\
\text { participating physicians } \\
\text { Conducted at the beginning and end of the project }\end{array}$ & - Audio recordings and transcriptions \\
\hline
\end{tabular}


and wind-down activities during the later months. Based on the activity logs when patient activities were at a peak, the $\mathrm{PN}$ helped 42 patients during a 2 -month period, with the number of tasks per patient ranging from 1 to 27 (mean, 6.3; SD, 6.6). PN tasks included making telephone calls to patients or family members, meeting patients in person in the office or at their homes $(\mathrm{n}=5)$, updating physicians, contacting other physicians, and researching and contacting community resources.

Overall, most patients were elderly (mean age, 72 years; SD, 17 years; range, 19-105 years), women, unmarried, white, and insured. The PN typically assessed patient needs by telephone. For 7 patients, a face-to-face needs assessment was con- ducted. Table 3 lists the different types of assistance provided by the PN.

The bulk of the activities focused on locating ancillary resources and arranging social services for elderly patients. In many cases the PN not only provided information about resources but also made phone calls to arrange appointments for patients. The focus of the PN on social services may have been reinforced by the physicians' assessments of her skills and background. Regarding the reason for many patients needing social services, one physician (MD1) noted that "part of it is her [social work] background and then part of it is it's easier to identify the patients who have social work problems, especially in a short-term research project."

Table 3. Navigation Assistance Provided by the Patient Navigator

\begin{tabular}{|c|c|}
\hline Issue & Assistance Provided \\
\hline $\begin{array}{l}\text { Choosing, understanding, and using health } \\
\text { coverage }\end{array}$ & $\begin{array}{l}\text { - Assisted with medical claim submissions } \\
\text { - Assisted with charity care applications } \\
\text { - Reviewed coverage of long-term care policies } \\
\text { - Reviewed Medicare requirements and provided assistance in obtaining specialized } \\
\text { equipment } \\
\text { - Obtained financial resources and information on social security benefits } \\
\text { - Identified pharmaceutical companies that provide free/low-cost drugs } \\
\text { - Researched options for coverage of organ transplantation } \\
\text { - Identified and referred patients to low-cost/free dental care } \\
\text { - Identified and referred patients to free bereavement counseling } \\
\text { - Assisted in applying for loan for air conditioning installation for disabled } \\
\text { - Obtained letter of necessity for physician }\end{array}$ \\
\hline $\begin{array}{l}\text { Choosing, using, and understanding health } \\
\text { providers and services }\end{array}$ & $\begin{array}{l}\text { - Made referrals for home health aides } \\
\text { - Identified adult day care centers and agencies providing live-in caregivers for } \\
\text { elderly } \\
\text { - Obtained information on assisted living facilities and low-cost senior housing } \\
\text { - Obtained and relayed information on guardianship and power of attorney } \\
\text { - Identified resources to help visually impaired patients } \\
\text { - Facilitated a blind patient's move to subsidized senior housing } \\
\text { - Obtained Meals on Wheels for patients } \\
\text { - Provided information on transportation services for doctor's appointments } \\
\text { - Obtained information on medic alert devices } \\
\text { - Located and referred to alcohol and substance abuse treatment programs } \\
\text { - Made referrals for child special education services } \\
\text { - Identified and referred patients to child and geriatric psychiatrists } \\
\text { - Identified and referred patients to difficult to find specialists (eg, autoimmune } \\
\text { specialist, physical therapy for balance problems) } \\
\text { - Located and coordinated low cost housekeeping services }\end{array}$ \\
\hline Making decisions about treatment & $\begin{array}{l}\text { - Provided emotional support and encouragement in obtaining psychological } \\
\text { counseling } \\
\text { - Obtained advance directives from patients } \\
\text { - Supported parents in sending child to residential treatment facility }\end{array}$ \\
\hline $\begin{array}{l}\text { Managing conditions and care received by } \\
\text { multiple providers }\end{array}$ & $\begin{array}{l}\text { - Followed up with specialists to obtain test results and reports } \\
\text { - Relayed information between patients/family members and physicians } \\
\text { - Assisted with phone calls for deaf patient going for surgery }\end{array}$ \\
\hline
\end{tabular}


Other activities included providing emotional support to patients and family members and enhancing communication between physicians and patients. Table 4 describes a sample case. In this case, the PN provided emotional support, researched insurance coverage, and obtained social services.

Maintaining boundaries with patients while still providing support was challenging for the PN. For example, on several occasions, the lead physician told her she was taking a lot of time with some patients, that she should just point them in the right direction and not perform social work. The PN reacted, "If we want to be...successful...you have to deal with every patient in a way that's appropriate for them. Some can just run with...a name and number, but the elderly are not able to go out on their own. The patient navigator should be able to use her judgment."

This issue may have manifest because the PN struggled to manage her role as a $\mathrm{PN}$ with her training as a social worker. There were a number of instances where, as a social worker, the PN would have gone farther in securing services for the patient. In these instances she was aware that role as a PN needed to be more limited and on occasion commented that what the patient needed was a social worker.

\section{Factors Affecting Coordination, Collaboration, and Integration}

Co-location

Although it was anticipated that the PN would spend a day per week in each office, lack of appro- priate office space precluded this. The PN spent most days in the one solo practice where, unlike the other practices, she did have workspace. One practice had only a kitchen area available for her, and another practice had a small room that was shared with pharmaceutical company representatives. Being co-located in the solo practice facilitated collaborative care. As the physician (MD1) reported, "She's more accessible to me than she is to the other 3 doctors because she uses this as her home base. So very often with the other doctors she is corresponding by email, and she has the ability to correspond with me by email to keep me up to date. But we also can huddle on a daily basis."

The PN typically visited the other practices once a week for no more than 20 minutes and mostly communicated with those physicians by telephone and email. Having an electronic medical record system in one practice facilitated this remote work. In another practice, the $\mathrm{PN}$ reported getting more out of the physician via email than when she was in the practice and the physician was busy seeing patients.

\section{Interaction with Practice Members}

In the solo practice, unlike in the other practices, the PN interacted with all members of the practice on patient care issues. In the other practices, the PN interacted almost exclusively with the participating physician about patients, and the PN took care of all the activities associated with this role: pulling files, contacting patients, and communicat-

\section{Table 4. Sample Case of Patient Whom the Patient Navigator Helped}

\begin{tabular}{|c|c|}
\hline $\begin{array}{l}\text { Patient characteristics and } \\
\text { background }\end{array}$ & $\begin{array}{l}\text { - Indigent, disabled, 61-year-old single woman } \\
\text { - Has diabetes, coronary artery disease, congestive heart failure requiring } \\
\text { implantable defibrillator, severe arthritis, and severe dental problems } \\
\text { - Subsisted on cereal because that was all she could eat and afford } \\
\text { - Window air conditioning unit broke and she was having difficulty breathing in the } \\
\text { summer heat }\end{array}$ \\
\hline Patient barriers & $\begin{array}{l}\text { - Financial: could not afford food, dental work, psychiatric counseling, installation } \\
\text { of donated central air conditioning unit } \\
\text { - Psychosocial: lacked social support, had fear and mistrust of dentists, depressed } \\
\text { (“All I was doing was waiting to die.") } \\
\text { - Transportation: had difficulty driving the long distance to see a psychiatrist and } \\
\text { could not afford gas }\end{array}$ \\
\hline Services provided by patient navigator & $\begin{array}{l}\text { - Obtained Meals on Wheels, resolving a catchment area dispute between } 2 \text { offices } \\
\text { - Provided an application for charity care for dental work } \\
\text { - Identified a psychiatrist that accepted Medicare for treatment of anxiety and } \\
\text { depression and arranged an appointment } \\
\text { - Obtained application for interest-free loan for air conditioner installation and } \\
\text { coordinated a letter of necessity from patient's physician } \\
\text { - Provided emotional support and encouragement to see the dentist } \\
\text { - Negotiated counseling at a nearby church when the patient declined treatment } \\
\text { from a psychiatrist and had difficulty driving to the appointment }\end{array}$ \\
\hline
\end{tabular}


ing coordination activities with patients, physicians, and resources. The physicians at these practices and the PN reported satisfaction with this arrangement. For example, one physician (MD3) stated, "I didn't anticipate that there would be a huge amount of interaction (with the staff), and...I don't think that is necessary at all....I don't think there is much that impacts the staff at all."

The PN agreed with this during a debriefing. "You refer a patient to me and then I independently go and figure out what I think-what the assessment is and get back to the doctor. I don't think I have to be involved with the mechanics of the offices...I can do my job fine without really being involved with the office staff."

However, another physician (MD4) stated that, "It would be great... if she could be here all the time...so if there's a patient with a problem I could say 'well let's walk down the hallway right now, we can have a chat with [the PN] and we'll get this straightened out."”

\section{The Process of Identifying and Referring Patients}

In the solo practice, the physician reported that the best way to identify patients in need of $\mathrm{PN}$ services was to have "the entire office team alerted to identify cases." However, in the other 3 practices, the PN relied solely on physicians for identification of patients. As the PN stated, "In [practice 1], it's more of a collaborative thing. [The doctor] doesn't do it just by himself. He'll have me come into a room, he'll have the office manager come in, and the 3 of us will sit there and go through this list... They're discussing the pros and cons of the situation with me there. So I'm hearing a lot more about the situation than just getting a little thumbnail...whereas with the other doctors, they just come up with the patients out of their own heads and tell me who the patients are and...why they're referring them."

This lack of staff collaboration with and even knowledge of the PN in some cases may have affected the PN's ability to follow through with some patients. As one patient (no. 411) reported, "I called up there to see if they knew who she was 'cause she'd say 'if I can help you'...[but] nobody in the office heard of her...I thought it was odd that she's representing him but the office doesn't know who she is."

\section{Perceived Value of Patient Navigation}

Patients/Family Members. Patients gained information and services that they would not otherwise have received, and they appreciated having someone call to check on them and provide information, support, and guidance. Some patients and family members reported feeling fortunate to receive this service and that having a PN service made them appreciate the office more. As one such patient (no. 150) reported, "It made me feel like they were a more caring, thoughtful office, somebody that I would want to continue to see on a regular basis because they had this extra help for their patients."

A few mentioned that speaking with the navigator made them feel better especially with regard to psychological distress. As one (patient no. 449) stated, "I'm going through a lot of depression.... and when I speak to her I feel much better."

Patients who reported having a good support network (ie, friends, family, community members with whom they had regular contact) reported not needing this service. As one patient (no. 209) stated, "She was sincerely caring and concerned and would have probably been more helpful to me had I not had a gazillion doctors and family."

Nonetheless, these patients were positive about the PN and could see how she would be helpful to others who did not have the capacity or support network they did.

Physicians. The PN was not conceived as filling an existing role in the practice but as someone who would be carrying out tasks that the practice was previously not doing, such as helping patients find needed resources and coordinating care beyond referral administration. Although one doctor felt the PN relieved her burden by assisting more demanding patients, others did not feel the $\mathrm{PN}$ relieved their burdens because she was providing extra services. Two of the physicians really liked having the PN focus on social services because, as one (MD3) put it, "It allowed me to participate in providing [social] services that I would have never been able to do on my own."

The other 2 physicians thought that $\mathrm{PN}$ services would be more useful if they focused on identifying and intervening with patients who are receiving fragmented care and on fostering population-based care, which the practice does not currently have the capacity to provide. As one physician (MD2) stated, "...I think [the social work] is an important piece. 
But $\mathrm{I}$ also see that there is a whole new area... where that person not only...can coordinate those pieces but also...can start to do some work with patients you're not seeing in the office."

These physicians reported that a nurse might be more appropriate than a social worker for this type of role. They acknowledged they would have probably referred different types of patients to the PN and had her concentrate more on tracking specialist testing and following patients after hospitalization if she were a nurse.

\section{Economics}

Most of the patients who were served by the PN reported that they either could not pay for the services or felt that, although the services were useful, they would not pay for these extra services. A few were willing to pay a nominal fee per service if the PN had more expertise in their needed area, such as mental health and Alzheimer disease. One family member was willing to pay as much as \$200 to have someone on call to talk to when needed.

When asked if they would hire a PN for their offices, physicians responded that they would like to but were unable to in the current payment environment. One physician (MD1) reported that he would hire a PN "if there was compensation for it, absolutely." As another physician (MD4) put it, "I would only do that if it was budget neutral for me. And since I couldn't charge or be reimbursed for her time then it...would come out of my pocket directly, and I've got enough competing things coming out of my pocket."

\section{Discussion}

We identified barriers and facilitators to the implementation and utilization of a $\mathrm{PN}$ in community primary care practices. This article is limited because it focuses on one individual working with a small number of physicians and providing services to only 75 mostly elderly patients; therefore, the results cannot be generalized broadly. Nevertheless, the challenges of integrating a $\mathrm{PN}$ into the existing primary care infrastructure are important to explore and discuss, especially because health care reform will involve changing structures of care. This pilot study helps us to understand these challenges.

Co-location and interaction with other practice members facilitated collaboration and integration of the PN in the solo practice. It was not surprising that integrating this new role in the group practices was difficult. Because the project involved only 1 physician in each practice and there was neither a location for the $\mathrm{PN}$ to work in these other practices nor interaction with other practice members, there was little incentive to change work processes within those practices. The PN worked in parallel to physicians in the group practices. However, in the solo practice there was collaboration and integration. The solo practice was the only one where the PN felt she was part of the health care team, and it was also the only practice where she met with patients in the office. This was because of limited space in the other practices. Although costs of adding staff or IT services are known barriers to achieving a $\mathrm{PCMH}$, the costs of adding workspace is often underappreciated. Our findings suggest that, in primary care practices, onsite space for in-person visits is a key element for successful coordination projects. This has been echoed in a recent Medicare demonstration project of 15 hospital-based care coordination programs, in which the 2 trials that were successful in decreasing hospitalizations and Medicare expenditures fostered close links between care coordinators and physicians, with care coordinators having onsite space in physician's offices for in-person visits with patients. ${ }^{17}$

The emphasis placed on delivering social work activities in this project may have been because of the PN's background as a social worker and the process of selecting and referring patients. Although there is debate about what type of personnel, qualifications, and training is optimal for a $\mathrm{PN},{ }^{9,18}$ who fulfills the $\mathrm{PN}$ role and the setting of care can greatly affect how patient navigation is operationalized, the type of patients who are assisted, and the services provided. ${ }^{14,19}$ Prospectively planning for optimal activities of the $\mathrm{PN}$ in the local environment would more clearly define the $\mathrm{PN}^{\prime}$ s role and help determine the best person to fulfill this role while preventing the confusion among patients, physicians, and the PN that occurred during this pilot project. Primary care transformation to a PCMH should be guided by a clear vision of patient needs and how the new role or function that's being considered will address those needs. In some environments a social worker might be the ideal candidate, depending on what the patients' needs are. In other practices that see many patients who have several comorbidities and who 
are seeing multiple specialists, a nurse might be preferred to help track specialist testing and care after hospitalizations.

The physicians in this study identified patients for referral proactively from their patient panel rather than at the point of contact. This may have led them to refer complex patients with social needs who were easier to identify. Complex patients may be falling through the cracks in the current health care system and may benefit from a social worker being a member of the health care team. Unfortunately, this is currently not available in small, community primary care practices.

Although a social worker or nurse coordinator may be a necessary member of the optimal health care team of PCMHs, ${ }^{5}$ making this role affordable and accessible to patients in small community practices requires different models of care and payment reforms, such as those advocated in the joint principles of the PCMH. ${ }^{4}$ More research is needed to demonstrate the cost savings or improved health outcomes that would motivate increased thirdparty payment for this new role in primary care settings. The value added by a PN may not be evidenced at the level of the individual provider, but perhaps more to the health care system as a whole through reduced utilization of health services. This may be more clearly measurable in terms of overall quality and costs of care in future health care systems, such as accountable care organizations, in which payments for patients are bundled across primary care and specialty care and outpatient and inpatient settings. ${ }^{20}$

Based on this pilot study, we do think a PN has the potential to foster collaborative care in primary care practices and to help patients overcome challenges of effectively and efficiently using our complex health system. We offer several recommendations based on our lessons learned. First, have a clear consensus of what patient navigation means to all participants and what new roles are required. Articulate a clear vision of patient needs and how the new role will address those needs. A person with both nursing and social work skills may be most optimal, and future training programs for this new role may be needed. Second, determine which patients should be a priority, such as the most vulnerable, the most expensive, those with the most to gain, or those who consume the majority of the clinician's time. It is important to distinguish tasks that add value to patients from those that will help reduce clinician burden (eg, telephone calls, paperwork, test results). Third, provide adequate workspace for new personnel. The PN being located in the office facilitates face-to-face meetings with patients (a key element of successful programs) ${ }^{17,21}$ and also helps introduce the new role to patients and practice members. This is especially important if the role is part-time or being shared with other practices. Finally, involve all practice members. Change in office workflow is needed for collaboration and integration of members to work as a team, and input from all involved is necessary for effective teamwork. ${ }^{22}$ A working model of how the PN will work with physicians and other practice staff should be prospectively articulated for effective integration to occur.

\section{Conclusion}

Services offered by a PN are valuable for patients who have complex needs, but integrating such services into primary care settings will require new practice and payment models to encourage practices to think differently about patient-centered care. Prospectively addressing the barriers to PN integration identified in this project will enhance success. Future research studies about patient navigation in primary care settings should evaluate process measures and patient assessments of access and coordination as well as improvements in outcomes, such as utilization, care quality, or healthrelated quality of life. Larger studies are needed to show effectiveness and cost-effectiveness before this model is broadly disseminated.

We thank Robert Eidus, MD; Thomas H. Kloos, MD; Samantha Pozner, MD; Paul B. Zukoff, MD, FACP; and Suzanne Sabini, MSW, for their participation in this study.

\section{References}

1. Backer LA. The medical home: an idea whose time has come. Again. Fam Pract Manag 2007;14:38-41.

2. Patient-Centered Primary Care Collaborative. Collaborative members. 2009. Available at: http://www. pcpcc.net/content/collaborative-members. Accessed 29 January 2009.

3. Committee on Quality of Health Care in America, Institute of Medicine. Crossing the quality chasm: a new health system for the 21 st century. Washington, D.C.: National Academy Press; 2001.

4. American Academy of Family Physicians, American Academy of Pediatrics, American College of Physicians, American Osteopathic Association. Joint principles of the 
patient-centered medical home. 2007. Available at: http:// www.medicalhomeinfo.org/Joint\%20Statement.pdf. Accessed 19 November 2007.

5. Stille CJ, Jerant A, Bell D, et al. Coordinating care across diseases, settings, and clinicians: a key role for the generalist in practice. Ann Intern Med 2005;142: $700-8$.

6. O'Malley AS, Peikes D, Ginsburg PB. Qualifying a physician practice as a medical home. Available at: http://www.hschange.com/CONTENT/1030/\#ib1. Accessed 15 September 2010.

7. Sofaer S. Navigating poorly charted territory: patient dilemmas in health care "nonsystems." Med Care Res Rev 2009;66(1 Suppl):75S-93S.

8. Dohan D, Schrag D. Using navigators to improve care of underserved patients: current practices and approaches. Cancer 2005;104:848-55.

9. Pedersen A, Hack TF. Pilots of oncology health care: a concept analysis of the patient navigator role. Oncol Nurs Forum 2010;37:55-60.

10. Wells KJ, Battaglia TA, Dudley DJ, et al. Patient navigation: state of the art or is it science? Cancer 2008;113:1999-2010.

11. Ferrante JM, Chen PH, Kim S. The effect of patient navigation on time to diagnosis, anxiety, and satisfaction in urban minority women with abnormal mammograms: a randomized controlled trial. J Urban Health 2008;85:114-24.

12. Lasser KE, Murillo J, Medlin E, et al. A multilevel intervention to promote colorectal cancer screening among community health center patients: results of a pilot study. BMC Fam Pract 2009;10:37.

13. Palmieri FM, DePeri ER, Mincey BA, et al. Comprehensive diagnostic program for medically underserved women with abnormal breast screening eval- uations in an urban population. Mayo Clin Proc 2009;84:317-22.

14. Campbell C, Craig J, Eggert J, Bailey-Dorton C. Implementing and measuring the impact of patient navigation at a comprehensive community cancer center. Oncol Nurs Forum 2010;37:61-8.

15. Nutting PA, Miller WL, Crabtree BF, Jaen CR, Stewart EE, Stange KC. Initial lessons from the first national demonstration project on practice transformation to a patient-centered medical home. Ann Fam Med 2009;7:254-60.

16. Crabtree B, Miller WL. Doing Qualitative Research, 2nd ed. Thousand Oaks, CA: Sage Publications; 1999.

17. Peikes D, Chen A, Schore J, Brown R. Effects of care coordination on hospitalization, quality of care, and health care expenditures among Medicare beneficiaries: 15 randomized trials. JAMA 2009;301:603-18.

18. Darnell JS. Patient navigation: a call to action. Soc Work 2007;52:81-4.

19. Vargas RB, Ryan GW, Jackson CA, Rodriguez R, Freeman HP. Characteristics of the original patient navigation programs to reduce disparities in the diagnosis and treatment of breast cancer. Cancer 2008; 113:426-33.

20. Rittenhouse DR, Shortell SM, Fisher ES. Primary care and accountable care-two essential elements of delivery-system reform. N Engl J Med 2009;361: 2301-3.

21. McAllister JW, Presler E, Cooley WC. Practicebased care coordination: a medical home essential. Pediatrics 2007;120:e723-33.

22. Crabtree BF, McDaniel RR, Nutting PA, Lanham HJ, Looney AJ, Miller WL. Closing the physicianstaff divide: a step toward creating the medical home. Fam Pract Manag 2008;15:20-4. 